\title{
Specific Detection of the Wheat Blast Pathogen (Magnaporthe oryzae Triticum) by Loop-Mediated Isothermal Amplification
}

Jarred Yasuhara-Bell, Department of Plant Pathology, Kansas State University, Manhattan 66506; Kerry F. Pedley, United States Department of Agriculture-Agricultural Research Service, Foreign Disease-Weed Science Research Unit, Fort Detrick, MD 21702; Mark Farman, Department of Plant Pathology, University of Kentucky, Lexington 40546; and Barbara Valent and James P. Stack, ${ }^{\dagger}$ Department of Plant Pathology, Kansas State University

\begin{abstract}
Wheat blast, caused by the Magnaporthe oryzae Triticum pathotype, is an economically important fungal disease of wheat. Wheat blast symptoms are similar to Fusarium head scab and can cause confusion in the field. Currently, no in-field diagnostic exists for M. oryzae Triticum. Loop-mediated isothermal amplification (LAMP) primers were designed to target the PoT2 and MoT3 loci, previously shown to be specific for $M$. oryzae and $M$. oryzae Triticum, respectively. Specificity was determined using $158 \mathrm{M}$. oryzae strains collected from infected wheat and other grasses and representing geographic and temporal variation. Negative controls included 50 Fusarium spp. isolates. Sensitivity was assessed using 10-fold serial dilutions of M. oryzae Triticum gDNA. PoT2- and

MoT3-based assays showed high specificity for $M$. oryzae and $M$. oryzae Triticum, respectively, and sensitivity to approximately $5 \mathrm{pg}$ of DNA per reaction. PoT2 and MoT3 assays were tested on M. oryzae Triticuminfected wheat seed and spikes and identified $M$. oryzae and $M$. oryzae Triticum, respectively, using a field DNA extraction kit and the portable Genie II system. The mitochondrial NADH-dehydrogenase (nad5) gene, an internal control for plant DNA, was multiplexed with PoT2 and MoT3 and showed results comparable with individual assays. These results show applicability for $M$. oryzae Triticum field surveillance, as well as identifying nonwheat species that may serve as a reservoir or source of inoculum for nearby wheat fields.
\end{abstract}

Wheat (Triticum spp.) is a grass grown for diverse applications, including biofuels, livestock feed, and human food (Shewry 2009). Wheat is highly adaptable and can grow in a variety of climates and elevations (Feldman 1995; Saunders 1994), making it an important food staple for many countries and cultures (Shewry 2009) and resulting in world trade often greater than all other crops combined (Curtis et al. 2002). It is one of the top three cereal crops produced worldwide and is grown on approximately 220 million ha (approximately 544 million acres), which is larger than the area for any other

${ }^{\dagger}$ Corresponding author: James P. Stack; E-mail: jstack@ksu.edu.

Funding: This work was supported by the Agriculture and Food Research Initiative (2009-55605-05201) and the United States Department of Agriculture National Institute of Food and Agriculture (2013-68004-20378).

Contribution number 18-324-J from the Kansas Agricultural Experiment Station.

Mention of trade names or commercial products in this publication is solely for the purpose of providing specific information and does not imply recommendation or endorsement by the U.S. Department of Agriculture.

The U.S. Department of Agriculture (USDA) prohibits discrimination in all its programs and activities on the basis of race, color, national origin, age, disability, and where applicable, sex, marital status, familial status, parental status, religion, sexual orientation, genetic information, political beliefs, reprisal, or because all or a part of an individual's income is derived from any public assistance program. (Not all prohibited bases apply to all programs.) Persons with disabilities who require alternative means for communication of program information (Braille, large print, audiotape, etc.) should contact USDA's TARGET Center at (202) 720-2600 (voice and TDD). To file a complaint of discrimination write to USDA, Director, Office of Civil Rights, 1400 Independence Avenue, SW, Washington, DC 20250-9410 or call (800) 795-3272 (voice) or (202) 720-6382 (TDD). USDA is an equal opportunity provider and employer.

*The $\boldsymbol{e}$-Xtra logo stands for "electronic extra" and indicates that one supplementary table is published online.

Accepted for publication 6 June 2018.

@ 2018 The American Phytopathological Society crop. In 2014, worldwide wheat production was approximately 730 million tons and valued at approximately US $\$ 192$ billion, with the top four wheat-producing countries being China (approximately 126 million tons), India (approximately 96 million tons), Russia (approximately 60 million tons), and the Unites States (approximately 55 million tons) (FAOSTAT 2014). Large-scale losses to wheat production can have devastating impacts on the global economy and food security.

Wheat blast, one of many diseases affecting wheat, is caused by the Triticum pathotype of Magnaporthe oryzae (synonymous with Pyricularia orzyae) (Couch and Kohn 2002; Zhang et al. 2016) and is considered a major disease affecting wheat production, with losses of up to $100 \%$ (Kohli et al. 2011; Peng et al. 2011) attributed to reduced yield and grain quality (Goulart et al. 2007) under conducive conditions (Anderson et al. 1947; Cardoso et al. 2008; Cruz and Valent 2017; Goulart et al. 2007; Urashima et al. 2009). Wheat blast disease was initially observed in 1985 in Paraná, Brazil (Igarashi et al. 1986; Maciel 2011) and subsequently in other areas in Brazil (Dos Anjos et al. 1996; Goulart et al. 1990; Igarashi 1990; Picinini and Fernandes 1990), Bolivia (Barea and Toledo 1996), Paraguay (Viedma 2005), and then Argentina (Perelló et al. 2015, 2017). The wheat blast pathogen was confined to South America until 2016, when it caused a widespread outbreak in Bangladesh (Callaway 2016; Malaker et al. 2016). Analyses of the strain causing the outbreak in Bangladesh suggested a close relation to aggressive M. oryzae Triticum isolates originating in South America (Islam et al. 2016; Malaker et al. 2016). These findings, combined with the knowledge that $M$. oryzae Triticum is seedborne (Goulart and Paiva 1990), raises concerns for widespread dissemination of $M$. oryzae Triticum to major wheat-producing areas of the world (Sadat and Choi 2017) such as India, China, and Russia, which are the top three wheat producers worldwide.

In the United States, wheat is one of the top four crop commodities (FAOSTAT 2014) and wheat blast disease caused by M. oryzae Triticum has not been reported to date. M. oryzae is subdivided into different pathotypes based on primary-host specificity (Couch et al. 2005; Farman 2002; Heath et al. 1990; Kato et al. 2000; Oh et al. 2002; Tosa et al. 2004; Urashima et al. 1993); however, M. oryzae pathotypes do infect and develop lesions on non-primary-host species (Dos Anjos and Charchar 2000; Farman 2002; Kohli et al. 2011; Tosa et al. 2004), causing confusion when surveying areas 
Table 1. Magnaporthe oryzae strains used in this study and corresponding loop-mediated isothermal amplification (LAMP) assay data

\begin{tabular}{|c|c|c|c|c|c|c|c|c|}
\hline \multirow{2}{*}{$\begin{array}{l}\text { Genotype group, } \\
\text { isolate }^{\mathrm{a}}\end{array}$} & \multirow[b]{2}{*}{ Host of isolation } & \multirow[b]{2}{*}{ Country } & \multirow[b]{2}{*}{ State or province } & \multirow{2}{*}{$\begin{array}{l}\text { Year } \\
\text { collected }\end{array}$} & \multirow{2}{*}{$\begin{array}{l}\text { Collector or } \\
\text { source }\end{array}$} & \multirow[b]{2}{*}{$\mathbf{M o T 3}^{\mathbf{b}}$} & \multicolumn{2}{|c|}{ LAMP data } \\
\hline & & & & & & & PoT2 & MoT3 \\
\hline \multicolumn{9}{|l|}{ Brachiaria } \\
\hline $\mathrm{Bm} 88324$ & $\begin{array}{l}\text { Brachiaria mutica (Mauritius signal } \\
\text { grass) }\end{array}$ & Philippines & Cabanatuan, Nueva Ecija & 1988 & R. Nelson & NT & + & - \\
\hline \multicolumn{9}{|l|}{ Cynodon ${ }^{c}$} \\
\hline $\mathrm{Cd} 88215^{\mathrm{c}}$ & Cynodon datylon (Bermuda grass) & Philippines & Cabanatuan, Nueva Ecija & 1988 & R. Nelson & NT & + & - \\
\hline \multicolumn{9}{|l|}{ Digitaria $^{c}$} \\
\hline Er88271 $1^{\mathrm{c}}$ & Eragrostis spp. & Philippines & Los Baños, Laguna & 1988 & R. Nelson & NT & + & - \\
\hline \multicolumn{9}{|l|}{ Echinochoa $^{c}$} \\
\hline $\mathrm{Ec} 88443^{\mathrm{c}}$ & Echinochoa colona (jungle rice) & Philippines & Los Baños, Laguna & 1988 & R. Nelson & NT & + & - \\
\hline \multicolumn{9}{|l|}{ Eleusine } \\
\hline B51 & Eleusine indica (goose grass) & Bolivia & Quirusillas & 2012 & Stack/Cruz & - & + & - \\
\hline $\begin{array}{l}\text { G22 (WGG- } \\
\text { FA40) }\end{array}$ & E. coracana (finger millet) & Japan & $\cdots$ & 1976 & $\begin{array}{l}\text { Yaegashi/ } \\
\text { Valent }\end{array}$ & - & + & - \\
\hline \multicolumn{9}{|l|}{ Eragrostis } \\
\hline G17 (K76-79) & $\begin{array}{l}\text { Eragrostis curvula (weeping } \\
\text { lovegrass) }\end{array}$ & Japan & $\cdots$ & 1976 & $\begin{array}{l}\text { Yaegashi/ } \\
\text { Valent }\end{array}$ & - & + & - \\
\hline \multicolumn{9}{|l|}{ Leersia $^{c}$} \\
\hline LhA8401 & $\begin{array}{l}\text { Leersia hexandra (southern } \\
\text { cutgrass) }\end{array}$ & Philippines & Los Baños, Laguna & 1984 & R. Nelson & NT & + & - \\
\hline \multicolumn{9}{|l|}{ Leptochloa $^{\mathrm{c}}$} \\
\hline LcA $8401^{c}$ & $\begin{array}{l}\text { Leptochloa chinensis (Chinese } \\
\text { sprangletop) }\end{array}$ & Philippines & Los Baños, Laguna & 1984 & R. Nelson & NT & + & - \\
\hline \multicolumn{9}{|l|}{ Lolium-Festuca } \\
\hline CHRF & Lolium perenne (perennial rygrass) & $\begin{array}{l}\text { United } \\
\text { States }\end{array}$ & Siler Springs, MD & 1996 & P. Dernoeden & - & + & - \\
\hline CHW & L. perenne & $\begin{array}{l}\text { United } \\
\text { States }\end{array}$ & $\begin{array}{l}\text { Annapolis/Severna Park, } \\
\text { MD }\end{array}$ & 1996 & P. Dernoeden & NT & + & - \\
\hline $\mathrm{FH}$ & L. perenne & $\begin{array}{l}\text { United } \\
\text { States }\end{array}$ & $\begin{array}{l}\text { Fountain Head/ } \\
\text { Hagerstown, MD }\end{array}$ & 1997 & P. Dernoeden & NT & + & - \\
\hline GG11 & L. perenne & $\begin{array}{l}\text { United } \\
\text { States }\end{array}$ & Lexington, KY & 1997 & P. Vincelli & - & + & - \\
\hline $\mathrm{HO}$ & L. perenne & $\begin{array}{l}\text { United } \\
\text { States }\end{array}$ & Richmond, PA & 1996 & P. Vincelli & - & + & - \\
\hline LpKY97 & L. perenne & $\begin{array}{l}\text { United } \\
\text { States }\end{array}$ & Lexington, KY & 1997 & P. Dernoeden & - & + & - \\
\hline P28 & Bromus tectorum (cheat grass) & Paraguay & Itapúa & $2012 / 2014$ & M. Kohli & - & + & - \\
\hline $\operatorname{Pg} 1213-22$ & Festuca arundinaceum (tall fescue) & $\begin{array}{l}\text { United } \\
\text { States }\end{array}$ & Georgia & $1999 / 2000$ & Tredway & - & + & - \\
\hline PL2-1 & L. multiforum (Italian ryegrass) & $\begin{array}{l}\text { United } \\
\text { States }\end{array}$ & Pulaski County, KY & 2002 & P. Vincelli & - & + & - \\
\hline PL3-1 & L. multiforum & $\begin{array}{l}\text { United } \\
\text { States }\end{array}$ & Pulaski County, KY & 2002 & J. Beale & - & + & - \\
\hline WBKY11-15 & Triticum aestivum (common wheat) & $\begin{array}{l}\text { United } \\
\text { States }\end{array}$ & Lexington, KY & 2011 & D. Hershman & - & + & - \\
\hline \multicolumn{9}{|l|}{ Oryza } \\
\hline GUY11 & Oryza sativa (Asian rice) & $\begin{array}{l}\text { French } \\
\text { Guyana }\end{array}$ & & 1988 & A. Ellingboe & NT & + & - \\
\hline IA1 (ARB114) & O. sativa & $\begin{array}{l}\text { United } \\
\text { States }\end{array}$ & Arkansas & 2009 & Y. Jia & NT & + & - \\
\hline IB49 (ZN61) & O. sativa & $\begin{array}{c}\text { United } \\
\text { States }\end{array}$ & Arkansas & 1992 & J. Correll & NT & + & - \\
\hline IC17 (ZN57) & O. sativa & $\begin{array}{l}\text { United } \\
\text { States }\end{array}$ & Arkansas & 1992 & J. Correll & NT & + & - \\
\hline IE1K (TM2) & O. sativa & $\begin{array}{l}\text { United } \\
\text { States }\end{array}$ & Arkansas & 2003 & T. Marchetti & NT & + & - \\
\hline INA168 & O. sativa & Japan & Aichi & 1985 & H. Kato & NT & + & - \\
\hline ML33 & O. sativa & Mali & $\ldots$ & 1995 & A. Ellingboe & NT & + & - \\
\hline \multicolumn{9}{|l|}{ Panicum ${ }^{c}$} \\
\hline $\operatorname{PrA} 8202^{\mathrm{c}}$ & Panicum repens (torpedograss) & Philippines & Los Baños, Laguna & 1982 & R. Nelson & NT & + & - \\
\hline \multicolumn{9}{|l|}{ Setaria } \\
\hline Arcadia & Setaria viridis (green foxtail) & $\begin{array}{l}\text { United } \\
\text { States }\end{array}$ & Lexington, KY & 1998 & M. Farman & NT & + & - \\
\hline & & & & & & (Continue & lon nex & $x t$ page $)$ \\
\hline
\end{tabular}

\footnotetext{
${ }^{a}$ Based on data provided by Gladieux et al. (2018).

${ }^{b}$ Based on data provided by Pieck et al. (2017); NT = was not tested

${ }^{c}$ Based on new whole genome sequence analyses (M. Farman, unpublished data).

d Strains not grouped by whole-genome sequencing.

e Only non- $M$. oryzae Triticum isolates found to possess the MoT3 locus by whole-genome sequencing. Strains appear to be hybrids of two genotype groups: Brachiaria and Stenotaphrum (M. Farman, unpublished data).
} 
Table 1. (Continued from previous page)

\begin{tabular}{|c|c|c|c|c|c|c|c|c|}
\hline \multirow{2}{*}{$\begin{array}{l}\text { Genotype group, } \\
\text { isolate }^{\mathrm{a}}\end{array}$} & \multirow[b]{2}{*}{ Host of isolation } & \multirow[b]{2}{*}{ Country } & \multirow[b]{2}{*}{ State or province } & \multirow{2}{*}{$\begin{array}{c}\text { Year } \\
\text { collected }\end{array}$} & \multirow{2}{*}{$\begin{array}{l}\text { Collector or } \\
\text { source }\end{array}$} & \multirow[b]{2}{*}{ MoT3 $^{\mathbf{b}}$} & \multicolumn{2}{|c|}{ LAMP data } \\
\hline & & & & & & & PoT2 & MoT3 \\
\hline GRF52 & S. viridis & $\begin{array}{l}\text { United } \\
\text { States }\end{array}$ & Lexington, KY & 2001 & M. Farman & NT & + & - \\
\hline \multicolumn{9}{|l|}{ Stenotaphrum } \\
\hline SSFL02-1 & $\begin{array}{l}\text { Stenotaphrum secundatum (St. } \\
\text { Augustine grass) }\end{array}$ & $\begin{array}{l}\text { United } \\
\text { States }\end{array}$ & Disneyworld, FL & 2002 & M. Farman & NT & + & - \\
\hline B2 & Triticum aestivum & Bolivia & Quirusillas & 2011 & Stack/Cruz & + & + & + \\
\hline B71 & T. aestivum & Bolivia & Quirusillas & 2012 & Stack/Cruz & NT & + & + \\
\hline Br80 & T. aestivum & Brazil & $\ldots$ & 1991 & D. Tharreau & NT & + & + \\
\hline P29 & B. tectorum & Paraguay & Itapúa & $2012 / 2014$ & M. Kohli & + & + & + \\
\hline P-3 & T. durum (durum wheat) & Paraguay & Canindeyu & 2012 & G. Peterson & + & + & + \\
\hline PY36.1 & T. aestivum & Brazil & Brasilia & 2007 & J. Maciel & + & + & + \\
\hline $\operatorname{Py} 22.1^{\mathrm{c}}$ & T. aestivum & Brazil & Paraná & 2007 & J. M. Fernandes & + & + & + \\
\hline PY5003 & T. aestivum & Brazil & Londrina & 2005 & J. Maciel & + & + & + \\
\hline $\mathrm{T} 25$ & T. aestivum & Brazil & Paraná & 1988 & S. Igarashi & + & + & + \\
\hline \multicolumn{9}{|l|}{ Not grouped $^{\mathrm{d}}$} \\
\hline BmA8309 & B. mutica & Philippines & Los Baños, Laguna & 1983 & R. Nelson & NT & + & - \\
\hline Bm88315 & B. mutica & Philippines & Cabanatuan, Nueva Ecija & 1988 & R. Nelson & NT & + & - \\
\hline Bm88509 & B. mutica & Philippines & Cabanatuan, Nueva Ecija & 1988 & R. Nelson & NT & + & - \\
\hline Bm88509 & B. mutica & Philippines & Cabanatuan, Nueva Ecija & 1988 & R. Nelson & NT & + & - \\
\hline $\mathrm{Bm} 88510$ & B. mutica & Philippines & Cabanatuan, Nueva Ecija & 1988 & R. Nelson & NT & + & - \\
\hline $\mathrm{Bm} 88511$ & B. mutica & Philippines & Cabanatuan, Nueva Ecija & 1988 & R. Nelson & NT & + & - \\
\hline $\mathrm{Bm} 88512$ & B. mutica & Philippines & Cabanatuan, Nueva Ecija & 1988 & R. Nelson & NT & + & - \\
\hline $\mathrm{Bm} 88513$ & B. mutica & Philippines & Cabanatuan, Nueva Ecija & 1988 & R. Nelson & NT & + & - \\
\hline P-0030 & Brachiaria spp. & Paraguay & Itapúa & 2014 & G. Peterson & - & + & - \\
\hline $\mathrm{Br} 35^{\mathrm{e}}$ & Brachiaria spp. & Brazil & Paraná & 1990 & S. Igarashi & NT & + & + \\
\hline $\mathrm{Cd} 88217$ & C. dactylon & Philippines & Cabanatuan, Nueva Ecija & 1988 & R. Nelson & NT & + & - \\
\hline CrA8401 & Cyperus rotundifolia (Cyperus root) & Philippines & Los Baños, Laguna & 1984 & R. Nelson & NT & + & - \\
\hline Dc8301 & $\begin{array}{l}\text { Digitaria ciliaris (southern } \\
\text { crabgrass) }\end{array}$ & Philippines & Los Baños, Laguna & 1983 & R. Nelson & NT & + & - \\
\hline B57 & Digitaria spp. & Bolivia & Quirusillas & 2012 & Stack/Cruz & - & + & - \\
\hline U167 & Digitaria spp. & Uruguay & Las Achiras, Lavalleja & 2010 & S. Martinez & NT & + & - \\
\hline $\mathrm{U} 227$ & Digitaria spp. & Uruguay & $\begin{array}{l}\text { Pueblo del Barro, } \\
\text { Tacuarembó }\end{array}$ & 2017 & S. Martinez & NT & + & - \\
\hline Ec883 & E. colona & Philippines & Bay, Laguna & 1988 & R. Nelson & NT & + & - \\
\hline U170 & Echinochloa spp. (barnyard grass) & Uruguay & Zapata, Treinta y Tres & 2010 & S. Martinez & NT & + & - \\
\hline EC4J & Eleusine coracana & Japan & $\ldots$ & 2015 & Y. Tosa & - & + & - \\
\hline EiA8303 & E. indica & Philippines & Los Baños, Laguna & 1983 & R. Nelson & NT & + & - \\
\hline Ei8927 & E. indica & Philippines & Bukidnon & 1989 & R. Nelson & NT & + & - \\
\hline Ei88435 & E. indica & Philippines & Tanauan, Batangas & 1988 & R. Nelson & NT & + & - \\
\hline Ei88365 & E. indica & Philippines & Sto. Tomas, Batangas & 1988 & R. Nelson & NT & + & - \\
\hline Ei88366 & E. indica & Philippines & Sto. Tomas, Batangas & 1988 & R. Nelson & NT & + & - \\
\hline Ei88367 & E. indica & Philippines & Sto. Tomas, Batangas & 1988 & R. Nelson & NT & + & - \\
\hline Ei88368 & E. indica & Philippines & Sto. Tomas, Batangas & 1988 & R. Nelson & NT & + & - \\
\hline Ei88369 & E. indica & Philippines & Sto. Tomas, Batangas & 1988 & R. Nelson & NT & + & - \\
\hline Ei88370 & E. indica & Philippines & Sto. Tomas, Batangas & 1988 & R. Nelson & NT & + & - \\
\hline Ei88424 & E. indica & Philippines & Sto. Tomas, Batangas & 1988 & R. Nelson & NT & + & - \\
\hline Ei88425 & E. indica & Philippines & Sto. Tomas, Batangas & 1988 & R. Nelson & NT & + & - \\
\hline Ei88448 & E. indica & Philippines & Tanauan, Batangas & 1988 & R. Nelson & NT & + & - \\
\hline $\mathrm{U} 228$ & E. indica & Uruguay & Valle Alto, Treinta y Tres & 2017 & S. Martinez & NT & + & - \\
\hline $\mathrm{U} 229$ & E. indica & Uruguay & Valle Alto, Treinta y Tres & 2017 & S. Martinez & NT & + & - \\
\hline $\mathrm{U} 231$ & E. indica & Uruguay & Valle Alto, Treinta y Tres & 2017 & S. Martinez & NT & + & - \\
\hline U169 & Eleusine spp. & Uruguay & Río Branco, Cerro Largo & 2010 & S. Martinez & NT & + & - \\
\hline P-0025 & Eragrostis spp. & Paraguay & Canindeyú & 2014 & G. Peterson & - & + & - \\
\hline $\operatorname{Pg} 1213-2$ & F. arundinaceum & $\begin{array}{l}\text { United } \\
\text { States }\end{array}$ & Georgia & $1999 / 2000$ & L. Tredway & - & + & - \\
\hline TFEGA & F. arundinaceum & $\begin{array}{l}\text { United } \\
\text { States }\end{array}$ & Kentucky & 2013 & M. Farman & - & + & - \\
\hline FPH2015-44e & $\begin{array}{l}\text { Hakonechloa macra (Japanese } \\
\text { forest grass) }\end{array}$ & $\begin{array}{l}\text { United } \\
\text { States }\end{array}$ & Ohio & 2015 & F. Hand & NT & + & + \\
\hline Lh8841 & Leersia hexandra & Philippines & Cabanatuan, Nueva Ecija & 1988 & R. Nelson & NT & + & - \\
\hline
\end{tabular}


Table 1. (Continued from previous page)

\begin{tabular}{|c|c|c|c|c|c|c|c|c|}
\hline \multirow{2}{*}{$\begin{array}{l}\text { Genotype group, } \\
\text { isolate }^{\mathrm{a}}\end{array}$} & \multirow[b]{2}{*}{ Host of isolation } & \multirow[b]{2}{*}{ Country } & \multirow[b]{2}{*}{ State or province } & \multirow{2}{*}{$\begin{array}{c}\text { Year } \\
\text { collected }\end{array}$} & \multirow{2}{*}{$\begin{array}{l}\text { Collector or } \\
\text { source }\end{array}$} & \multirow[b]{2}{*}{ MoT3 $^{b}$} & \multicolumn{2}{|c|}{ LAMP data } \\
\hline & & & & & & & PoT2 & MoT3 \\
\hline Lh8982 & L. hexandra & Philippines & Los Baños, Laguna & 1989 & R. Nelson & NT & + & - \\
\hline Lh88405 & L. hexandra & Philippines & Los Baños, Laguna & 1988 & R. Nelson & NT & + & - \\
\hline Lh88504 & L. hexandra & Philippines & Cabanatuan, Nueva Ecija & 1988 & R. Nelson & NT & + & - \\
\hline $\mathrm{U} 221$ & L. multiflorum & Uruguay & Berachi, Cerro Largo & 2017 & S. Martinez & NT & + & - \\
\hline $\mathrm{U} 234$ & L. multiflorum & Uruguay & 18 de Julio, Rocha & 2017 & S. Martinez & NT & + & - \\
\hline $\mathrm{U} 235$ & L. multiflorum & Uruguay & 18 de Julio, Rocha & 2017 & S. Martinez & NT & + & - \\
\hline $\mathrm{U} 236$ & L. multiflorum & Uruguay & 18 de Julio, Rocha & 2017 & S. Martinez & NT & + & - \\
\hline $\mathrm{U} 237$ & L. multiflorum & Uruguay & UEPL, Treinta y Tres & 2017 & S. Martinez & NT & + & - \\
\hline $\mathrm{U} 238$ & L. multiflorum & Uruguay & UEPL, Treinta y Tres & 2017 & S. Martinez & NT & + & - \\
\hline LpNC17-1 & L. perenne & $\begin{array}{l}\text { United } \\
\text { States }\end{array}$ & Asheville, NC & 2017 & M. Farman & NT & + & - \\
\hline MoLFP136 & L. perenne & $\begin{array}{l}\text { United } \\
\text { States }\end{array}$ & Marysville, KS & 2007 & M. Kennedy & NT & + & - \\
\hline MoLFP137 & L. perenne & $\begin{array}{l}\text { United } \\
\text { States }\end{array}$ & Trampis, KS & 2007 & M. Kennedy & NT & + & - \\
\hline MoLFP138 & L. perenne & $\begin{array}{l}\text { United } \\
\text { States }\end{array}$ & Prairie Dunes, KS & 2007 & M. Kennedy & NT & + & - \\
\hline PgVC1.4.2 & L. perenne & $\begin{array}{l}\text { United } \\
\text { States }\end{array}$ & New York & 2001 & W. Uddin & - & + & - \\
\hline U168 & Luziola spp. (watergrass) & Uruguay & Río Branco, Cerro Largo & 2010 & S. Martinez & NT & + & - \\
\hline U171 & Luziola spp. & Uruguay & Zapata, Treinta y Tres & 2010 & S. Martinez & NT & + & - \\
\hline O-249 & O. sativa & India & Cuttack, Orissa & 1986 & Bonman/Valent & NT & + & - \\
\hline $\mathrm{O}-250$ & O. sativa & India & Hydrabad & 1986 & Bonman/Valent & NT & + & - \\
\hline O-260 & O. sativa & Nepal & Kathmandu Valley & 1987 & Bonman/Valent & NT & + & - \\
\hline O-261 & O. sativa & Nepal & Kathmandu Valley & 1987 & Bonman/Valent & NT & + & - \\
\hline O-282 & O. sativa & Brazil & Goiania & 1987 & Bonman/Valent & NT & + & - \\
\hline O-283 & O. sativa & Brazil & Goiania & 1987 & Bonman/Valent & NT & + & - \\
\hline RB-1 & O. sativa & $\begin{array}{l}\text { United } \\
\text { States }\end{array}$ & Glen County, CA & 2009 & Kosta & - & + & - \\
\hline $\mathrm{RB}-2$ & O. sativa & Korea & $\ldots$ & 2011 & K. Pedley & - & + & - \\
\hline RB-3 & O. sativa & Philippines & $\ldots$ & 2011 & K. Pedley & - & + & - \\
\hline SSID116 & O. sativa & $\begin{array}{l}\text { United } \\
\text { States }\end{array}$ & Louisiana & 2013 & Y. Jia & NT & + & - \\
\hline U75 & O. sativa & Uruguay & UEPL, Treinta y Tres & 2005 & S. Martinez & NT & + & - \\
\hline UB107 & O. sativa & Uruguay & $\begin{array}{l}\text { Charqueada, Treinta y } \\
\text { Tres }\end{array}$ & 2009 & S. Martinez & NT & + & - \\
\hline U198 & O. sativa & Uruguay & $\begin{array}{l}\text { Cinco Sauces, } \\
\text { Tacuarembó }\end{array}$ & 2014 & S. Martinez & NT & + & - \\
\hline $\operatorname{Pd} 8824$ & Paspalum distichum (knotgrass) & Philippines & Cabanatuan, Nueva Ecija & 1988 & R. Nelson & NT & + & - \\
\hline $\operatorname{Pd} 8825$ & P. distichum & Philippines & Cabanatuan, Nueva Ecija & 1988 & R. Nelson & NT & + & - \\
\hline $\operatorname{Pd} 8826$ & P. distichum & Philippines & Cabanatuan, Nueva Ecija & 1988 & R. Nelson & NT & + & - \\
\hline $\operatorname{Pd} 8827$ & P. distichum & Philippines & Cabanatuan, Nueva Ecija & 1988 & R. Nelson & NT & + & - \\
\hline $\operatorname{Pd} 8828$ & P. distichum & Philippines & Cabanatuan, Nueva Ecija & 1988 & R. Nelson & NT & + & - \\
\hline $\operatorname{Pd} 8829$ & P. distichum & Philippines & Cabanatuan, Nueva Ecija & 1988 & R. Nelson & NT & + & - \\
\hline $\operatorname{Pd} 8830$ & P. distichum & Philippines & Cabanatuan, Nueva Ecija & 1988 & R. Nelson & NT & + & - \\
\hline $\operatorname{Pd} 8831$ & P. distichum & Philippines & Cabanatuan, Nueva Ecija & 1988 & R. Nelson & NT & + & - \\
\hline $\operatorname{Pd} 8832$ & P. distichum & Philippines & Cabanatuan, Nueva Ecija & 1988 & R. Nelson & NT & + & - \\
\hline $\operatorname{Pd} 8833$ & P. distichum & Philippines & Cabanatuan, Nueva Ecija & 1988 & R. Nelson & NT & + & - \\
\hline Pd8834 & P. distichum & Philippines & Cabanatuan, Nueva Ecija & 1988 & R. Nelson & NT & + & - \\
\hline $\operatorname{Pd} 8835$ & P. distichum & Philippines & Cabanatuan, Nueva Ecija & 1988 & R. Nelson & NT & + & - \\
\hline $\operatorname{Pd} 8836$ & P. distichum & Philippines & Cabanatuan, Nueva Ecija & 1988 & R. Nelson & NT & + & - \\
\hline $\operatorname{Pd} 8837$ & P. distichum & Philippines & Cabanatuan, Nueva Ecija & 1988 & R. Nelson & NT & + & - \\
\hline $\operatorname{Pd} 8838$ & P. distichum & Philippines & Cabanatuan, Nueva Ecija & 1988 & R. Nelson & NT & + & - \\
\hline $\operatorname{Pd} 8841$ & P. distichum & Philippines & Cabanatuan, Nueva Ecija & 1988 & R. Nelson & NT & + & - \\
\hline $\operatorname{Pd} 8843$ & P. distichum & Philippines & Cabanatuan, Nueva Ecija & 1988 & R. Nelson & NT & + & - \\
\hline $\operatorname{Pr} 88171$ & P. repens & Philippines & Cabanatuan, Nueva Ecija & 1988 & R. Nelson & NT & + & - \\
\hline $\operatorname{Pr} 889$ & P. repens & Philippines & Bay, Laguna & 1988 & R. Nelson & NT & + & - \\
\hline $\operatorname{Pr} 8988$ & P. repens & Philippines & Los Baños, Laguna & 1989 & R. Nelson & NT & + & - \\
\hline $\operatorname{Pr} 88165$ & P. repens & Philippines & Cabanatuan, Nueva Ecija & 1989 & R. Nelson & NT & + & - \\
\hline $\operatorname{Pr} 88167$ & P. repens & Philippines & Cabanatuan, Nueva Ecija & 1988 & R. Nelson & NT & + & - \\
\hline $\operatorname{Pr} 88168$ & P. repens & Philippines & Cabanatuan, Nueva Ecija & 1988 & R. Nelson & NT & + & - \\
\hline $\operatorname{Pr} 88169$ & P. repens & Philippines & Cabanatuan, Nueva Ecija & 1988 & R. Nelson & NT & + & - \\
\hline $\operatorname{Pr} 88170$ & P. repens & Philippines & Cabanatuan, Nueva Ecija & 1988 & R. Nelson & NT & + & - \\
\hline GF7 (SS1) & Setaria faberi (giant foxtail) & $\begin{array}{l}\text { United } \\
\text { States }\end{array}$ & Lexington, $\mathrm{KY}$ & & M. Farman & - & + & - \\
\hline
\end{tabular}


Table 1. (Continued from previous page)

\begin{tabular}{|c|c|c|c|c|c|c|c|c|}
\hline \multirow{2}{*}{$\begin{array}{l}\text { Genotype group, } \\
\text { isolate }^{\mathrm{a}}\end{array}$} & \multirow[b]{2}{*}{ Host of isolation } & \multirow[b]{2}{*}{ Country } & \multirow[b]{2}{*}{ State or province } & \multirow{2}{*}{$\begin{array}{c}\text { Year } \\
\text { collected }\end{array}$} & \multirow{2}{*}{$\begin{array}{l}\text { Collector or } \\
\text { source }\end{array}$} & \multirow[b]{2}{*}{ MoT3 $^{b}$} & \multicolumn{2}{|c|}{ LAMP data } \\
\hline & & & & & & & PoT2 & MoT3 \\
\hline $\mathrm{U} 232$ & S. italica (foxtail millet) & Uruguay & Minas, Lavalleja & 2017 & S. Martinez & NT & + & - \\
\hline GrF57 & S. viridis & $\begin{array}{l}\text { United } \\
\text { States }\end{array}$ & Lexington, KY & 2001 & M. Farman & NT & + & - \\
\hline YF DC & S. viridis & $\begin{array}{l}\text { United } \\
\text { States }\end{array}$ & Lexington, $\mathrm{KY}$ & 2013 & M. Farman & - & + & - \\
\hline A-0005 & S. secundatum & $\begin{array}{l}\text { United } \\
\text { States }\end{array}$ & Spanish Plaza, AL & 2012 & Olive & - & + & - \\
\hline LD2 & S. secundatum & $\begin{array}{l}\text { United } \\
\text { States }\end{array}$ & FL & 2006 & L. Datnoff & - & + & - \\
\hline $\operatorname{Pg} 1054$ & S. secundatum & $\begin{array}{l}\text { United } \\
\text { States }\end{array}$ & Parrot, GA & 2000 & L. Tredway & NT & + & - \\
\hline SSTX16-1 & S. secundatum & $\begin{array}{l}\text { United } \\
\text { States }\end{array}$ & College Station, TX & 2016 & D. Ebbole & NT & + & - \\
\hline $\mathrm{U} 217$ & S. secundatum & Uruguay & Valle Alto, Treinta y Tres & 2015 & S. Martinez & NT & + & - \\
\hline $\mathrm{U} 224$ & S. secundatum & Uruguay & Santa Teresa, Rocha & 2014 & S. Martinez & NT & + & - \\
\hline U233 & S. secundatum & Uruguay & Covidef 1, Florida & 2017 & S. Martinez & NT & + & - \\
\hline UF0822 & S. secundatum & $\begin{array}{l}\text { United } \\
\text { States }\end{array}$ & FL & 2008 & L. Datnoff & - & + & - \\
\hline $\mathrm{B} 50$ & T. aestivum & Bolivia & Quirusillas & 2012 & Stack/Cruz & NT & + & + \\
\hline B53 & T. aestivum & Bolivia & Quirusillas & 2012 & Stack/Cruz & NT & + & + \\
\hline B54 & T. aestivum & Bolivia & Quirusillas & 2012 & Stack/Cruz & NT & + & + \\
\hline P-16 & T. aestivum & Paraguay & Alto Paraná & 2012 & Peterson/Kohli & NT & + & + \\
\hline Py22.1 & T. aestivum & Brazil & Paraná & 2007 & J. M. Fernandes & + & + & + \\
\hline PY5020 & T. aestivum & Brazil & Londrina & 2005 & J. M. Fernandes & + & + & + \\
\hline T-0002 & T. aestivum & Brazil & PR & 1987 & A. S. Prabhu & + & + & + \\
\hline $\mathrm{T}-0050$ & T. aestivum & Brazil & MG & 1989 & S. Igarashi & + & + & + \\
\hline
\end{tabular}

for disease or potential sources of inoculum. A fitting example occurred in the United States in 2011, when M. oryzae was isolated from a single wheat spike showing symptoms of wheat blast in Kentucky (Farman et al. 2017). M. oryzae Triticum was not reported in the United States; thus, this finding was cause for concern. Extensive analyses of the infecting isolate (WBKY11-15) revealed that it was more closely related to native ryegrass populations of $M$. oryzae (Lolium pathotype) than to South American M. oryzae Triticum strains (Farman et al. 2017). Further disease surveys did not identify a second occurrence (Cruz and Valent 2017). However, these findings suggested a close relationship between Lolium and Triticum pathotypes (Farman 2002; Farman et al. 2017; Tosa et al. 2004; Viji et al. 2001) and revealed a potential risk not only from importing aggressive strains of $M$. oryzae Triticum from South America but also from cross-host infection by indigenous Lolium pathotypes (Cruz and Valent 2017).

Control measures for this disease are limited and require a multifaceted approach. There are many unanswered questions regarding the factors that enable epidemics. Surveying fields and nearby areas for disease and latent infections could identify or prevent potential outbreaks. This would also involve screening and identifying alternative hosts harboring the pathogen as potential sources of inoculum. This method requires the proper identification of the disease as well as the causal agent. Additionally, screening seed and certifying it M. oryzae Triticum-free will reduce the risk of further international spread. These approaches require a powerful diagnostic tool and there is no standardized molecular detection assay for identifying M. oryzae Triticum in the field. There is a need for such an assay, because in-field whole-genome sequence (WGS) analysis for identification is not yet practical.

Fusarium head blight (FHB), or scab of wheat, caused by Fusarium graminearum, is another disease that impacts global wheat production and produces symptoms similar to wheat blast (McMullen et al. 1997). A proper diagnostic tool would differentiate between $F$. graminearum and $M$. oryzae. Recently, the PoT2 transposon (Farman 2002; George et al. 1998; Harmon et al. 2003; Kachroo et al. 1994) was used in a polymerase chain reaction (PCR)-based diagnostic platform to detect $M$. oryzae at the species level (Pieck et al.
2017) and discriminate $M$. oryzae from other genera of fungi. However, the PoT2 locus does not differentiate among pathotypes of $M$. oryzae. A diagnostic assay is needed to distinguish the Triticum pathotype from all other $M$. oryzae pathotypes. Correct identification of M. oryzae Triticum will allow proper phytosanitary measures to be implemented to prevent further spread of M. oryzae Triticum, as well as to track or trace outbreaks originating from foreign sources. An end-point and real-time PCR assay using the MoT3 locus of the retinol dehydrogenase gene for detection of $M$. oryzae Triticum has been published (Pieck et al. 2017). In the current study, the PoT2 transposon and MoT3 locus were used to develop loopmediated isothermal amplification (LAMP) assays for the specific detection of $M$. oryzae Triticum in-lab and in the field. LAMP is a technology that allows nucleic acid amplification under isothermal conditions, enabling rapid detection in the laboratory and field using a variety of methods and instrumentation for running reactions and viewing results (Notomi et al. 2000).

\section{Materials and Methods}

Fungal specimens and DNA isolation. All work with active M. oryzae Triticum strains was performed in a BSL-3 biocontainment laboratory at the Biosecurity Research Institute in Pat Roberts Hall at Kansas State University in compliance with United States Department of Agriculture-Animal and Plant Health Inspection Service Plant Protection and Quarantine permit conditions (P526P-1501607); only $M$. oryzae Triticum DNA was used outside of containment. M. oryzae strains used in this study are shown in Table 1 and all other strains tested are shown in Table 2. Magnaporthe strains were grown as described previously (Pieck et al. 2017). DNA was isolated from lyophilized fungal tissue using a phenol chloroform extraction or the OmniPrep for Fungi DNA extraction kit (G-Biosciences, St. Louis). Fusarium strains were grown and DNA extracted according to a method published previously (Leslie and Summerell 2006). DNA was quantified using the Qubit 3.0 Fluorometer (ThermoFisher Scientific Life Technologies, Waltham, MA, USA) and working solutions were made at $1 \mathrm{ng} / \mu \mathrm{l}$.

LAMP primer design and reaction conditions. Based on previous studies, the PoT2 locus (Farman 2002; George et al. 1998; 
Harmon et al. 2003; Kachroo et al. 1994; Pieck et al. 2017) and MoT3 locus (Pieck et al. 2017) were chosen as targets for specific detection of all $M$. oryzae and only $M$. oryzae Triticum strains, respectively. The mitochondrial NADH-dehydrogenase (nad5) gene (Ecke et al. 1990) was chosen as an internal control for plant DNA. LAMP primers (Table 3) were designed using PrimerExplorer V5 (Eiken Chemical Co., Ltd., Tokyo), available at http://primerexplorer.jp/e/. Individual LAMP reactions contained $5 \mu l$ of sample, $5 \mu l$ of primer master mix ( $1 \mu \mathrm{M}$ F3, $1 \mu \mathrm{M}$ B3, $8 \mu \mathrm{M}$ FIP, $8 \mu \mathrm{M}$ BIP, $4 \mu \mathrm{M}$ each Loop, $0.4 \mu \mathrm{M}$ Probe, and $0.8 \mu \mathrm{M}$ Quencher Probe [Kubota et al. 2011]) and $15 \mu \mathrm{l}$ of Isothermal Mastermix ISO-001nd (OptiGene, West Sussex, UK). Multiplexed Nad5/PoT2 LAMP reactions used $2.5 \mu \mathrm{l}$ of primer master mix (modified concentrations of $3 \mu \mathrm{M}$ Nad5-LoopB, $3.2 \mu \mathrm{M}$ PoT2-LoopB, $1 \mu \mathrm{M}$ each Nad5-Probe, $0.8 \mu \mathrm{M}$ each PoT2-Probe, and 3.6 $\mu \mathrm{M}$ Quencher Probe [Kubota et al. 2011]) and $17.5 \mu \mathrm{l}$ of Isothermal Mastermix ISO-001nd. Multiplexed Nad5/MoT3 LAMP reactions used $2.5 \mu \mathrm{l}$ of primer master mix (modified concentrations of $3 \mu \mathrm{M}$ Nad5-LoopB, $2 \mu \mathrm{M}$ MoT3LoopB, $1 \mu \mathrm{M}$ each Nad5-Probe, $2 \mu \mathrm{M}$ each MoT3-Probe, and $6 \mu \mathrm{M}$ Quencher Probe [Kubota et al. 2011]) and $17.5 \mu \mathrm{l}$ of Isothermal Mastermix ISO-001nd. Positive and negative controls used $5 \mu \mathrm{l}$ of $M$. oryzae or $M$. oryzae Triticum DNA and double-distilled water $\left(\mathrm{ddH}_{2} \mathrm{O}\right)$ or pathogen-free sample, respectively. All LAMP reactions, except Nad5/MoT3, were run and analyzed using the CFX96 RealTime System (Bio-Rad, Hercules, CA, USA) at $65^{\circ} \mathrm{C}$ for $30 \mathrm{~min}$, with fluorescence readings taken at 1-min intervals. Nad5/MoT3 assays were run for $50 \mathrm{~min}$, to account for delayed or shifted reaction curves. Individual reactions containing carboxyfluorescein (FAM) probes were also run in the Genie II (OptiGene).

Assay specificity and sensitivity testing. Primer specificity was determined using $40 \mathrm{M}$. oryzae strains assigned to 14 hostspecialized groups (M. Farman, unpublished data) and 118 unassigned strains (Table 1). Fifty-one isolates of other fungi composed the exclusivity panel (Table 2), which included several Fusarium spp. (Sarver et al. 2011) commonly found on wheat spikes. The sensitivity of these primers was determined using 10-fold serial dilutions of DNA working solution (M. oryzae Triticum strain T25) at $1 \mathrm{ng} / \mu \mathrm{l}$ down to $1 \mathrm{fg} / \mu \mathrm{l}$, which corresponded to DNA at $5 \mathrm{ng}$ down to $5 \mathrm{fg} /$ reaction, respectively. LAMP reactions were performed as individual and multiplexed assays, as described above. Reactions were run in triplicate. This process was repeated to include wheat DNA in each reaction to assess any possible effects of extraneous DNA on sensitivity.

Plant inoculation and sample testing. $M$. oryzae Loliuminoculated (MoLFP136) seed were prepared according to a protocol established by J. Kiyuna (personal communication). Total DNA was extracted using the Quick-DNA Fungal/Bacterial Miniprep Kit and a field extraction kit (Plant Material Lysis Kit; OptiGene). M. oryzae Triticum-inoculated (B71) plant material (wheat spikes) was prepared, according to a protocol established previously (Cruz et al. 2012, 2016). Seed infected naturally with $M$. oryzae Triticum from Quirusillas, Santa Cruz, Bolivia in 2014 was also tested. Symptomatic spike samples and naturally infected seed ( 1 and 5 seeds) were processed using the Plant Material Lysis Kit. Noninoculated seed or plant materials were used as negative controls. Processed samples were tested by individual and multiplexed LAMP assays, as described above.

Interlaboratory reproducibility testing. LAMP reagents for individual PoT2 and MoT3 assays (FAM) and representative DNA samples were sent to three National Plant Diagnostic Network (Stack et al. 2014) laboratories: the Institute of Food and Agricultural Sciences Plant Diagnostic Center at the University of Florida, Michigan State University, and the School of Integrated Plant Sciences at Cornell University. Ten samples were tested under blind conditions. Assays were performed in the QuantStudio3 (Applied Biosystems, ThermoFisher Scientific, Waltham, MA, USA), QuantStudio6 (Applied Biosystems, ThermoFisher Scientific), and StepOnePlus (Applied Biosystems, ThermoFisher Scientific) at Cornell University, the University of Florida, and Michigan State University, respectively. Results were reported from these laboratories and then assessed by comparing data to known strain or assay information.

\section{Results}

Assay specificity and sensitivity. Results from this study corroborate those produced by Pieck et al. (2017) using end-point PCR. The PoT2 LAMP primer set was specific at the species level and reacted with all M. oryzae strains. The MoT3 LAMP primer set was specific for the M. oryzae Triticum pathotype (Table 1), with two exceptions (isolates FPH-2015-44 and Br35). Although not true wheat blast pathogens, isolates FPH-2015-44 and Br35 possess the MoT3 locus (M. Farman, unpublished data). Additionally, these two strains grouped between Brachiaria and Stenotrophum groups, suggesting these strains are hybrids of the two pathotypes (M. Farman, unpublished data). Thus far, WGS has not identified other non-M. oryzae Triticum strains containing the MoT3 locus (M. Farman, unpublished data). No positive reactions were observed with the negative controls or with non-M. oryzae strains (Table 2).

The PoT2 and MoT3 LAMP assays could detect as few as 5 pg of DNA per reaction, even in the presence of wheat DNA. There were no differences in sensitivity when FAM was used instead of rhodamine X (ROX) and cyanine 5 (Cy5) for PoT2 and MoT3, respectively. Additionally, the sensitivity of these primer sets was identical when tested in the CFX96 Real-Time System and Genie II. Multiplexed assays were sensitive to as few as $50 \mathrm{pg}$ of DNA per reaction and resulted in a slight delay in reaction time. This shift in sensitivity is typical in multiplexed reactions.

Plant sample testing. The PoT2 and MoT3 LAMP assays functioned properly when testing seed and spike samples, regardless of the DNA preparation kit used. Sensitivity of the PoT2 LAMP assay was sufficient to yield positive detection of $M$. oryzae Lolium from single seeds, using both the Quick-DNA Fungal/Bacterial Miniprep Kit and Plant Material Lysis Kit. Both reactions failed to detect $M$. oryzae Triticum in a single naturally infected seed processed with the Plant Material Lysis Kit, even using a modified protocol to prevent overdilution of the sample $(40 \mu \mathrm{l}$ of sample instead of $10 \mu \mathrm{l})$. Both assays were able to detect $M$. oryzae Triticum from the naturally infected seed lot when 5 seeds were processed together, using the manufacturers' protocol. No reactions were observed for any of the negative controls, which included healthy wheat seed and spikes, rye seed, and oat seed, as well as $\mathrm{dd}_{2} \mathrm{O}$.

The Nad5 LAMP primers were used as a plant DNA control and positive reactions were only observed in samples containing plant material. The Nad5/PoT2 assay was able to detect M. oryzae Lolium in a single inoculated seed when processed by the Quick-DNA Fungal/Bacterial Miniprep Kit but not the Plant Material Lysis Kit. This was most likely due to the reduction in sensitivity of the multiplexed reaction. Detection of $M$. oryzae Lolium in a single inoculated seed processed with the Plant Material Lysis Kit was obtained by modifying the manufacturer's protocol to prevent overdilution of the sample $(40 \mu \mathrm{l}$ of sample instead of $10 \mu \mathrm{l})$. Both multiplex reactions were able to detect $M$. oryzae Triticum from an infected spike. Multiplexed assays also detected $M$. oryzae Triticum from 5 infected seeds processed with the Plant Material Lysis Kit, using a modified protocol $(40 \mu \mathrm{l}$ of sample instead of $10 \mu \mathrm{l})$. The Nad5/ PoT2 assay produced predicted results using the 30-min protocol, most likely due to it being a multicopy target; however, the Nad5/ MoT3 assay needed a 50-min protocol, being a single-copy target in a multiplex reaction. These results demonstrate applicability for field studies using a field-isolation kit and portable real-time amplification system, because field samples will include multiple infected seed and plant material, ensuring enough pathogen present in samples to allow detection.

Interlaboratory reproducibility testing. All data reported from each of the three laboratories (Supplementary Table S1) were congruent with each other and data presented in Table 1, reflecting the accuracy of the PoT2 and MoT3 LAMP assays in identifying $M$. oryzae and M. oryzae Triticum, respectively. Additionally, each laboratory performed the assays in a SmartCycler (Cepheid, Sunnyvale, CA, USA) for $30 \mathrm{~min}$ with optics off for $53 \mathrm{~s}$ and optics on for $7 \mathrm{~s}$. The SmartCycler was able to produce accurate results; however, further optimization is required for use in this platform. Based on these results, its small sample capacity $(n=16)$, and the fact that Cepheid 
will no longer support this platform, it is recommended that this system not be used.

\section{Discussion}

$M$. oryzae is subdivided into pathotypes based on primary host specificity: Brachiaria (signal grass), Eleusine (finger millet), Eragrotis (lovegrass), Lolium (turfgrasses), Oryza (rice), Setaria (foxtail millet), Stenotaphrum (St. Augustine grass), and Triticum (wheat) pathotypes (Couch et al. 2005; Farman 2002; Gladieux et al. 2018; Heath et al. 1990; Kato et al. 2000; Oh et al. 2002; Tosa et al. 2004; Urashima et al. 1993). The strains used this study were chosen to represent a wide range of isolates from different hosts, times, and geographic locations, as well as inclusion in previous studies (Gladieux et al. 2018; Pieck et al. 2017). Strains used by Pieck et al. (2017) were included to check if the LAMP primers could produce specificity results comparable with those produced by PCR primers developed in that study. However, a major problem facing proper identification of $M$. oryzae Triticum is the fact that $M$. oryzae pathotypes can also infect or reside on hosts that are not their primary host. Therefore, host of isolation does not accurately represent pathotype and extensive pathogenicity tests have not been performed on many
M. oryzae isolates. Strains used by Gladieux et al. (2018) were included in this study to take advantage of WGS genome-group data, which were used in the absence of pathogenicity data to suggest pathotype, regardless of host of isolation.

The PoT2 and MoT3 primers designed in this study demonstrated high specificity for $M$. oryzae and $M$. oryzae Triticum, respectively. Three isolates from wheat (WBKY11-15, PY5010, and PY86.1; the latter two not tested in this study) showed potential false negatives with the MoT3 assay; although isolated from wheat, these strains grouped with the Lolium-Festuca clade by WGS (Gladieux et al. 2018) and, consequently, are likely true negatives. Only one true false negative has been identified; wheat blast isolate $\mathrm{Br} 32$ does not possess the MoT3 locus and should not be detectable with either the PCR or LAMP assays (M. Farman, unpublished data). Two potential false positives were identified by LAMP (isolates FPH2015-44 and Br35), and any strain producing positive results in a region without wheat blast would have to be confirmed by in-depth methods such as WGS. Taken together, the specificity data obtained in this study suggest that these primers, as well as the PoT2 and MoT3 loci, are useful tools for identification of the wheat blast pathogen (M. oryzae Triticum) in the field.

Table 2. Non-Magnaporthe oryzae strains used in this study and corresponding loop-mediated isothermal amplification data

\begin{tabular}{|c|c|c|c|c|c|c|c|c|}
\hline Organism $^{a}$ & Isolate & Host & Country & State or province & $\begin{array}{c}\text { Year } \\
\text { collected }\end{array}$ & Collector & PoT2 & MoT3 \\
\hline Fusarium aethiopicum & 46710 & Triticum aestiveum & $\cdots$ & $\cdots$ & 2012 & $\begin{array}{l}\text { O'Donnell// } \\
\text { Bowden }\end{array}$ & - & - \\
\hline F. aethiopicum & 46718 & T. aestiveum & $\cdots$ & $\cdots$ & 2012 & $\begin{array}{l}\text { O'Donnell/ } \\
\text { Bowden }\end{array}$ & - & - \\
\hline F. aethiopicum & 46726 & T. aestiveum & $\ldots$ & $\ldots$ & 2012 & $\begin{array}{l}\text { O'Donnell/ } \\
\text { Bowden }\end{array}$ & - & - \\
\hline F. asiaticum & NRRL6101 & T. aestiveum & $\begin{array}{c}\text { United } \\
\text { States }\end{array}$ & Peoria, IL & 2010 & & - & - \\
\hline F. asiaticum & NRRL28720 & T. aestiveum & $\begin{array}{l}\text { United } \\
\text { States }\end{array}$ & Peoria, IL & 2010 & & - & - \\
\hline F. boothii & NRRL26916 & T. aestiveum & $\begin{array}{l}\text { United } \\
\text { States }\end{array}$ & Peoria, IL & 2010 & & - & - \\
\hline F. gerlachii & 36905 & T. aestiveum & $\ldots$ & $\ldots$ & 2012 & $\begin{array}{l}\text { O'Donnell/ } \\
\text { Bowden }\end{array}$ & - & - \\
\hline F. gerlachii & 38380 & T. aestiveum & $\ldots$ & $\ldots$ & 2012 & $\begin{array}{l}\text { O'Donnell/ } \\
\text { Bowden }\end{array}$ & - & - \\
\hline F. gerlachii & 38405 & T. aestiveum & $\ldots$ & $\cdots$ & 2012 & $\begin{array}{l}\text { O'Donnell/ } \\
\text { Bowden }\end{array}$ & - & - \\
\hline F. graminearum & $00-540 \mathrm{M}$ & T. aestiveum & $\ldots$ & $\ldots$ & 2004 & L. Gale & - & - \\
\hline F. graminearum & $00-566 \mathrm{M}$ & T. aestiveum & $\ldots$ & $\ldots$ & 2004 & L. Gale & - & - \\
\hline F. graminearum & $00-649 \mathrm{M}$ & T. aestiveum & $\ldots$ & $\ldots$ & 2004 & L. Gale & - & - \\
\hline F. graminearum & 3653 & T. aestiveum & $\begin{array}{l}\text { United } \\
\text { States }\end{array}$ & $\begin{array}{l}\text { Nemaha County, } \\
\text { KS }\end{array}$ & 1990 & & - & - \\
\hline F. graminearum & 5 kernel & T. aestiveum & $\begin{array}{l}\text { United } \\
\text { States }\end{array}$ & $\begin{array}{l}\text { Shawnee County, } \\
\text { KS }\end{array}$ & 2012 & E. DeWolff & - & - \\
\hline F. graminearum & COX 66 & T. aestiveum & Brazil & $\begin{array}{l}\text { Coxilha, Passo } \\
\text { Fundo }\end{array}$ & $\ldots$ & $\ldots$ & - & - \\
\hline F. graminearum & CX101 & T. aestiveum & Germany & $\ldots$ & 2004 & T. Miedaner & - & - \\
\hline F. graminearum & CX153 & T. aestiveum & Germany & $\ldots$ & 2004 & T. Miedaner & - & - \\
\hline F. graminearum & CX38 & T. aestiveum & Brazil & $\begin{array}{l}\text { Coxilha, Passo } \\
\text { Fundo }\end{array}$ & $\cdots$ & $\ldots$ & - & - \\
\hline F. graminearum & D036 & T. aestiveum & $\begin{array}{l}\text { United } \\
\text { States }\end{array}$ & Elkland, IL & 2008 & B. Bowden & - & - \\
\hline F. graminearum & FG108 & T. aestiveum & Germany & $\ldots$ & 2004 & T. Miedaner & - & - \\
\hline F. graminearum & FG3211 & T. aestiveum & Germany & $\ldots$ & 2004 & T. Miedaner & - & - \\
\hline F. graminearum & FG96 & T. aestiveum & Germany & $\ldots$ & 2004 & T. Miedaner & - & - \\
\hline F. graminearum & $\begin{array}{c}\text { FRC-R- } \\
6221\end{array}$ & T. aestiveum & Australia & New South Wales & 2006 & $\ldots$ & - & - \\
\hline F. graminearum & H001 & T. aestiveum & $\begin{array}{l}\text { United } \\
\text { States }\end{array}$ & New York & 1999 & B. Bowden & - & - \\
\hline F. graminearum & MRC4712 & T. aestiveum & Germany & $\ldots$ & 2004 & W. Marassas & - & - \\
\hline \multirow[t]{2}{*}{ F. graminearum } & MRC6010 & T. aestiveum & Germany & $\ldots$ & 2004 & W. Marassas & - & - \\
\hline & & & & & & \multicolumn{3}{|c|}{ (Continued on next page) } \\
\hline
\end{tabular}

a The $F$. graminearum species complex contains 16 phylogenetically distinct species (Sarver et al. 2011).

${ }^{\mathrm{b}} \mathrm{GCP}=$ Gulf coast population 
The sensitivities of the LAMP primers designed in this study were $5 \mathrm{pg} /$ reaction, similar to those published in other studies. This level of sensitivity is expected when compared with LAMP assays designed to detect bacteria, which tend to be between 1 and $100 \mathrm{fg}$ of DNA per reaction. Fungal genomes are much larger than bacterial genomes and usually comprise multiple chromosomes; therefore, the target gene/DNA mass ratio will be substantially lower, thus resulting in a lower relative sensitivity.

The cumulative results of this study demonstrate the utility of the PoT2- and MoT3-based LAMP assays for laboratory and field applications. The PoT2 assay could be used as a general screening assay to detect all $M$. oryzae pathotypes. Upon finding a positive reaction, the MoT3 assay could be used to confirm the presence of true M. oryzae Triticum. Under the current capabilities of the Genie II, the PoT2 and MoT3 assays would have to be run individually using FAM probes. The Nad5/PoT2 assay could be used in the field as a preliminary assay to detect the presence of $M$. oryzae, using a device capable of running two multiplexed reactions. The MoT3 or Nad5/MoT3 assay could then be used as a confirmatory assay to determine whether the detected M. oryzae strain is true M. oryzae Triticum. Additionally, the Nad5/MoT3 assay could be deployed alone to detect $M$. oryzae Triticum in fields located in endemic areas where $M$. oryzae is established. Individual reactions cost less than US\$1 per reaction, while the multiplexed assays cost approximately US $\$ 1.20$. Cost per reaction could decrease following further optimization.

Future work will involve field testing in South America, particularly in Bolivia and Brazil, where wheat blast is common and many $M$. oryzae pathotypes are present. Wheat fields could be surveyed for $M$. oryzae and M. oryzae Triticum using the LAMP assays described in this article. In addition, surrounding fields and plants could be checked for infection with M. oryzae and M. oryzae Triticum. In particular, Brachiaria fields that are grown as a forage crop and are located near commercial wheat fields could be surveyed for the presence of $M$. oryzae and $M$. oryzae Triticum, because this plant has been identified as a possible primary $M$. oryzae Triticum-inoculum source for wheat fields located in Brazil (J. M. C. Fernandes, personal communication). These assays could also be used to survey surrounding areas to determine the extent of spread of M. oryzae Triticum from diseased fields. This would be particularly useful in areas surrounding outbreaks in Bangladesh to determine areas affected by spreading $M$. oryzae Triticum from diseased regions.

Table 2. (Continued from previous page)

\begin{tabular}{|c|c|c|c|c|c|c|c|c|}
\hline Organism $^{a}$ & Isolate & Host & Country & State or province & $\begin{array}{c}\text { Year } \\
\text { collected }\end{array}$ & Collector & PoT2 & MoT3 \\
\hline F. graminearum & NRRL13383 & T. aestiveum & $\begin{array}{l}\text { United } \\
\text { States }\end{array}$ & Peoria, IL & 2010 & $\cdots$ & - & - \\
\hline F. graminearum & NRRL28063 & T. aestiveum & $\begin{array}{l}\text { United } \\
\text { States }\end{array}$ & Peoria, IL & 2010 & $\cdots$ & - & - \\
\hline F. graminearum & NRRL28336 & T. aestiveum & $\begin{array}{l}\text { United } \\
\text { States }\end{array}$ & Peoria, IL & 2010 & $\cdots$ & - & - \\
\hline F. graminearum & NRRL28439 & T. aestiveum & $\begin{array}{l}\text { United } \\
\text { States }\end{array}$ & Peoria, IL & 2010 & $\cdots$ & - & - \\
\hline F. graminearum & NRRL6394 & T. aestiveum & $\begin{array}{l}\text { United } \\
\text { States }\end{array}$ & Peoria, IL & 2010 & $\cdots$ & - & - \\
\hline F. graminearum & NZ425 & $\begin{array}{l}\text { Chionochloa rubra ssp. } \\
\text { cuprea (Red tussock grass) }\end{array}$ & $\begin{array}{l}\text { New } \\
\text { Zealand }\end{array}$ & South Island & $\cdots$ & A. Bentley & - & - \\
\hline F. graminearum & NZ427 & C. rubra ssp. cuprea & $\begin{array}{l}\text { New } \\
\text { Zealand }\end{array}$ & South Island & $\cdots$ & A. Bentley & - & - \\
\hline F. graminearum & PF00-30 & T. aestiveum & Brazil & Passo Fundo & $\ldots$ & $\ldots$ & - & - \\
\hline F. graminearum & PF99-41 & T. aestiveum & Brazil & Passo Fundo & $\ldots$ & $\ldots$ & - & - \\
\hline F. graminearum & PF99-47 & T. aestiveum & Brazil & Passo Fundo & $\ldots$ & $\ldots$ & - & - \\
\hline F. graminearum & PT-1-04Fg & T. aestiveum & $\begin{array}{l}\text { United } \\
\text { States }\end{array}$ & $\begin{array}{r}\text { Pottawatomie } \\
\text { County, KS }\end{array}$ & $\cdots$ & M. Davis & - & - \\
\hline F. graminearum & VAC 84 & T. aestiveum & Brazil & Vacaria & $\ldots$ & $\ldots$ & - & - \\
\hline F. graminearum & VAC-2 & T. aestiveum & Brazil & Vacaria & $\ldots$ & $\ldots$ & - & - \\
\hline $\begin{array}{l}\text { F. graminearum } \\
\text { subpopulation } \mathrm{GCP}^{\mathrm{b}}\end{array}$ & 29149 & T. aestiveum & $\ldots$ & $\cdots$ & 2012 & $\begin{array}{l}\text { O'Donnell/ } \\
\text { Bowden }\end{array}$ & - & - \\
\hline $\begin{array}{l}F \text {. graminearum } \\
\text { subpopulation } \mathrm{GCP}^{\mathrm{b}}\end{array}$ & 38369 & T. aestiveum & $\cdots$ & $\cdots$ & 2012 & $\begin{array}{l}\text { O’Donnell/ } \\
\text { Bowden }\end{array}$ & - & - \\
\hline $\begin{array}{l}\text { F. graminearum } \\
\text { subpopulation } \mathrm{GCP}^{\mathrm{b}}\end{array}$ & 38371 & T. aestiveum & $\ldots$ & $\cdots$ & 2012 & $\begin{array}{l}\text { O'Donnell/ } \\
\text { Bowden }\end{array}$ & - & - \\
\hline F. lousianense & 54196 & T. aestiveum & $\begin{array}{l}\text { United } \\
\text { States }\end{array}$ & $\begin{array}{l}\text { Jefferson Davis } \\
\text { Parish, LA }\end{array}$ & 2012 & $\begin{array}{l}\text { O’Donnell/ } \\
\text { Bowden }\end{array}$ & - & - \\
\hline F. proliferatum & Fp-70-2-5 & Z. mays (corn) & $\begin{array}{l}\text { United } \\
\text { States }\end{array}$ & Manhattan, KS & $\cdots$ & Reyes-Gaige & - & - \\
\hline F. ussurianum & 45681 & T. aestiveum & $\cdots$ & $\cdots$ & 2012 & $\begin{array}{l}\text { O’Donnell/ } \\
\text { Bowden }\end{array}$ & - & - \\
\hline F. ussurianum & 45795 & T. aestiveum & $\cdots$ & $\cdots$ & 2012 & $\begin{array}{l}\text { O’Donnell/ } \\
\text { Bowden }\end{array}$ & - & - \\
\hline F. verticillioides & Fv-54-3-5 & Z. mays & $\begin{array}{l}\text { United } \\
\text { States }\end{array}$ & Manhattan, KS & $\cdots$ & Reyes-Gaige & - & - \\
\hline F. vorosii & 37605 & T. aestiveum & $\cdots$ & $\ldots$ & 2012 & $\begin{array}{l}\text { O'Donnell/ } \\
\text { Bowden }\end{array}$ & - & - \\
\hline F. vorosii & 38207 & T. aestiveum & $\ldots$ & $\cdots$ & 2012 & $\begin{array}{l}\text { O'Donnell/ } \\
\text { Bowden }\end{array}$ & - & - \\
\hline F. vorosii & 38208 & T. aestiveum & $\cdots$ & $\cdots$ & 2012 & $\begin{array}{l}\text { O'Donnell/ } \\
\text { Bowden }\end{array}$ & - & - \\
\hline Magnaporthe pennisetigena & Ce88454 & $\begin{array}{l}\text { Cenchrus echinatus } \\
\text { (southern sandbur) }\end{array}$ & Philippines & $\cdots$ & 1988 & $\cdots$ & - & - \\
\hline
\end{tabular}


Table 3. Oligonucleotide primers used in this study

\begin{tabular}{|c|c|c|}
\hline $\begin{array}{l}\text { Oligonucleotide } \\
\text { primer }\end{array}$ & Sequence $\left(5^{\prime}-3^{\prime}\right)^{\mathbf{a}}$ & Source or reference \\
\hline Nad5-F3 & ACACATTCCGACGATTGGC & This study \\
\hline Nad5-B3 & CCGGTCTTAACGCCCCTA & This study \\
\hline Nad5-FIP & ACCAACCAAAGCAGGTAGGCGAAAGTGGATCTGTTGTGCGA & This study \\
\hline Nad5-BIP & GGCTCCTCCGTTGTGGGTAAACTGTGCAGCCTTTCCTCG & This study \\
\hline Nad5-LoopF & CCACGGTTCATAACGCACTCT & This study \\
\hline Nad5-LoopB & CGGGAAACCCGACTCTACG & This study \\
\hline Nad5-Probe & /56-FAM/ACGCTGAGGACCCGGATGCGAATGCGGATGCGGATGCCGACGGGAAACCCGACTCTACG & This study \\
\hline PoT2-F3 & AATTACGCTTTTTTGCCGA & This study \\
\hline PoT2-B3 & GGTTTAATAGCGTTAATAACCGG & This study \\
\hline PoT2-FIP & GAGCCAAAAAACGAGTTATCCAACGACGAATTCTTCAAGCCGC & This study \\
\hline PoT2-BIP & AАTCCTTAAAACCCAAAGGCCCACCAAGATTTAATTACCTCCGT & This study \\
\hline PoT2-LoopF & CCAAGGCCTTTTGTCTCTCCG & This study \\
\hline PoT2-LoopB & CGTCGAATAGATAACGCCCGG & This study \\
\hline PoT2-Probe ${ }^{b}$ & $\begin{array}{l}\text { /56-ROXN/ } \\
\text { ACGCTGAGGACCCGGATGCGAATGCGGATGCGGATGCCGACGTCGAATAGATAACGCCCGG }\end{array}$ & This study \\
\hline MoT3-F3 & CCAAGGATGTATGCCCTGAC & This study \\
\hline MoT3-B3 & GTTGGGGGCTTCGTATGC & This study \\
\hline MoT3-FIP & CAAACCGTTAGAAAGCTGTACTTCAGTTGTTACAACATCACGAATCG & This study \\
\hline MoT3-BIP & TTGCACAAAACAACCCAGTTCAGAGACGTTGTTTATGAATTCCG & This study \\
\hline MoT3-LoopB & CTTTTGCATCGCCGAGCC & This study \\
\hline MoT3-Probe ${ }^{b}$ & /5Cy5/ACGCTGAGGACCCGGATGCGAATGCGGATGCGGATGCCGACTTTTGCATCGCCGAGCC & This study \\
\hline Quencher probe & TCGGCATCCGCATCCGCATTCGCATCCGGGTCCTCAGCGT/3BHQ_1/ & Kubota et al. 2011 \\
\hline
\end{tabular}

a /56-FAM/ = 5'6-carboxyfluorescein, /56-ROXN/ = 5'6-rhodamine X, /5Cy5/ = 5' cyanine 5, and /3BHQ_1/ = 3' Black Hole Quencher 1.

${ }^{\mathrm{b}} \mathrm{FAM}$ probes were substituted for ROX and Cy5 when using the Genie II.

In addition to M. oryzae Triticum, some M. oryzae Lolium strains cause disease in wheat, under laboratory conditions, with strain WBKY11-15 causing blast disease naturally; therefore, M. oryzae Lolium should not be overlooked (Farman et al. 2017). A LAMP assay was designed to detect $M$. oryzae Lolium from perennial ryegrass (Lolium perenne) (Villari et al. 2017). However, the M. oryzae Lolium LAMP assay specificity was determined against a small number of isolates that did not represent all major pathotypes of $M$. oryzae, with $M$. oryzae Triticum not being included in the study due to quarantine issues (Villari et al. 2017). Further studies should be done to optimize this $M$. oryzae Lolium LAMP assay for field detection. A multiplexed assay could then be produced that could detect M. oryzae and determine whether M. oryzae Lolium or M. oryzae Triticum was present in the sample. Additionally, the occurrence of the MoT3 locus in a few non-Triticum pathotype strains may suggest a potential for false-positive detections in practice. Hence, there is a need to identify additional $M$. oryzae Triticum-unique markers to complement the MoT3-based assay for identification of true $M$. oryzae Triticum. Moreover, extensive pathogenicity testing of isolates to determine virulence on different host species is needed to properly sort them into pathotypes and, thus, establish a level of agreement between WGS-based genomic-grouping and current molecular diagnostic assays.

\section{Acknowledgments}

We thank A. Ruck, M. Dalby, and Y. Tosa (strain Br35) for providing M. oryzae DNA; B. Kruse, B. Ramundo, and J. Leslie for providing F. graminearum DNA; J. Kiyuna for providing $M$. oryzae Lolium-colonized seed; G. Cruppe for providing M. oryzae Triticum-infected plant material; and S. Bec (University of Florida), J. Byrne (Michigan State University), and M. Ann Karp (Cornell University) for performing the independent laboratory testing of the assays.

\section{Literature Cited}

Anderson, A., Henry, B., and Tullis, E. 1947. Factors affecting infectivity, spread and persistence of Pyricularia oryzae Cav. Phytopathology 37:94-110.

Barea, G., and Toledo, J. 1996:Pages 76-86 in: Identificación y zonificación de Pyricularia o brusone (Pyricularia oryzae) en el cutivo de trigo en el departamento de Santa Cruz. Centro de Investigación Agrícola Tropical, Informe Tecnico, Proyecto de Investigacion Trigo, Santa Cruz de la Sierra, Bolivia.

Callaway, E. 2016. Devastating wheat fungus appears in Asia for the first time. Nature 532:421-422.
Cardoso, C. D. A., Reis, E. M., and Moreira, E. N. 2008. Development of a warning system for wheat blast caused by Pyricularia grisea. Summa Phytopathol. 34:216-221.

Couch, B. C., Fudal, I., Lebrun, M. H., Tharreau, D., Valent, B., Van Kim, P., Nottéghem, J. L., and Kohn, L. M. 2005. Origins of host-specific populations of the blast pathogen Magnaporthe oryzae in crop domestication with subsequent expansion of pandemic clones on rice and weeds of rice. Genetics 170:613-630.

Couch, B. C., and Kohn, L. M. 2002. A multilocus gene genealogy concordant with host preference indicates segregation of a new species, Magnaporthe oryzae, from $M$. grisea. Mycologia 94:683-693.

Cruz, C. D., Bockus, C. C., Stack, J. P., Tang, X., Valent, B., Pedley, K. F., and Peterson, G. L. 2012. Preliminary assessment of resistance among U.S. wheat cultivars to the Triticum Pathotype of Magnaporthe oryzae. Plant Dis. 96: 1501-1505

Cruz, C. D., Bockus, C. C., Stack, J. P., and Valent, B. 2016. A standardized inoculation protocol to test wheat cultivars for reaction to head blast caused by Magnaporthe oryzae (Triticum pathotype). Plant Health Prog. 17:186-187.

Cruz, C. D., and Valent, B. 2017. Wheat blast disease: Danger on the move. Trop Plant Pathol. 42:210-222.

Curtis, B. C., Rajaram, S., and Gómez, M. 2002. Bread Wheat: Improvement and Production. Food and Agriculture Organization of the United Nations (FAO)

Dos Anjos, J. R. N., and Charchar, M. J. A. 2000. Natural infection of barley by Pyricularia grisea in Brazil. Fitopatol. Bras. 25:205-208.

Dos Anjos, J. R. N., da Silva, D. B., Charchar, M. J. D., and Rodrigues, G. C. 1996 Occurrence of blast fungus (Pyricularia grisea) on wheat and rye in the savanna region of central Brazil. Pesqui. Agropecu. Bras. 31:79-82.

Ecke, W., Schmitz, U., and Michaelis, G. 1990. The mitochondrial nad5 gene of sugar beet (Beta vulgaris) encoding a subunit of the respiratory NADH dehydrogenase. Curr. Genet. 18:133-139.

FAOSTAT. 2014. Food and Agricultural Commodities Production.

Farman, M., Peterson, G., Chen, L., Starnes, J., Valent, B., Bachi, P., Murdock, L., Hershman, D., Pedley, K. F., Fernandes, J. M., and Bavaresco, J. 2017. The Lolium pathotype of Magnaporthe oryzae recovered from a single blasted wheat plant in the United States. Plant Dis. 101:684-692.

Farman, M. L. 2002. Pyricularia grisea isolates causing gray leaf spot on perennial ryegrass (Lolium perenne) in the United States: Relationship to P. grisea isolates from other host plants. Phytopathology 92:245-254.

Feldman, M. 1995. Wheats. Pages 185-192 in: Evolution of Crop Plants. J. Smartt and M. J. Simmonds, eds. Longman Scientific and Technical, Harlow, UK

George, M. L. C., Nelson, R. J., Zeigler, R. S., and Leung, H. 1998. Rapid population analysis of Magnaporthe grisea by using rep-PCR and endogenous repetitive DNA sequences. Phytopathology 88:223-229.

Gladieux, P., Condon, B., Ravel, S., Soanes, D., Leodato, J., Maciel, N., Nhani, A., Jr., Terauchi, R., Lebrun, M.-H., Tharreau, D., Mitchell, T., Pedley, K. F. Valent, B., Talbot, N. J., Farman, M., and Fournier, E. 2018. Gene flow 
between divergent cereal- and grass-specific lineages of the rice blast fungus Magnaporthe oryzae. MBio 9:e01219-e17.

Goulart, A. C. P., and Paiva, F. A. 1990. Transmission of Pyricularia oryzae by wheat Triticum aestivum seeds. Fitopatol. Bras. 26:1983-1988.

Goulart, A. C. P., Paiva, F. A., and Mesquita, A. N. 1990. Occurrence of wheat blast Pyricularia oryzae in the state of Mato Grosso so Sul Brazil. Fitopatol. Bras. 15:112-114.

Goulart, A. C. P., Sousa, P. G., and Urashima, A. S. 2007. Danos em trigo causados pela infecção de Pyricularia grisea [Damages in wheat caused by infection of Pyricularia grisea]. Summa Phytopathol. 33:358-363.

Harmon, P. F., Dunkle, L. D., and Latin, R. 2003. A rapid PCR-based method for the detection of Magnaporthe oryzae from infected perennial ryegrass. Plant Dis. 87:1072-1076.

Heath, M. C., Valent, B., Howard, R. J., and Chumley, F. G. 1990. Interactions of two strains of Magnaporthe grisea with rice, goosegrass, and weeping lovegrass. Can. J. Bot. 68:1627-1637.

Igarashi, S. 1990. Update on wheat blast (Pyricularia oryzae) in Brazil. Pages 480-483 in: Wheat for the Nontraditional Warm Areas: Proc. Int. Conf. Foz do Iguaçu, Paraná, Brazil. D. A. Saunders, ed.

Igarashi, S., Utiamada, C. M., Igarashi, L. C., Kazuma, A. H., and Lopes, R. S. 1986. Pyricularia em trigo. 1. Ocorrência de Pyricularia sp. no estado do Paraná. Fitopatol. Bras. 11:351-352.

Islam, M. T., Croll, D., Gladieux, P., Soanes, D. M., Persoons, A., Bhattacharjee, P., Hossain, M. S., Gupta, D. R., Rahman, M. M., Mahboob, M. G., Cook, N., Salam, M. U., Surovy, M. Z., Sancho, V. B., Maciel, J. L. N., Nhani, A., Castroagudin, V. L., Reges, J. T. D., Ceresini, P. C., Ravel, S., Kellner, R., Fournier, E., Tharreau, D., Lebrun, M. H., McDonald, B. A., Stitt, T., Swan, D., Talbot, N. J., Saunders, D. G. O., Win, J., and Kamoun, S. 2016. Emergence of wheat blast in Bangladesh was caused by a South American lineage of Magnaporthe oryzae. BMC Biol. 14:84.

Kachroo, P., Leong, S. A., and Chattoo, B. B. 1994. Pot2, an inverted repeat transposon from the rice blast fungus Magnaporthe grisea. Mol. Gen. Genet. 245:339-348.

Kato, H., Yamamoto, M., Yamaguchi-Ozaki, T., Kadouchi, H., Iwamoto, Y., Nakayashiki, H., Tosa, Y., Mayama, S., and Mori, N. 2000. Pathogenicity, mating ability and DNA restriction fragment length polymorphisms of Pyricularia populations isolated from Gramineae, Bambusideae and Zingiberaceae plants. J. Gen. Plant Pathol. 66:30-47.

Kohli, M. M., Mehta, Y. R., Guzman, E., De Viedma, L., and Cubilla, L. E. 2011. Pyricularia blast-A threat to wheat cultivation. Czech J. Genet. Plant Breed. 47:S130-S134.

Kubota, R., Alvarez, A. M., Su, W. W., and Jenkins, D. M. 2011. FRET-based assimilating probe for sequence-specific real-time monitoring of loop-mediated isothermal amplification (LAMP). Biol. Eng. Trans. 4:81-100.

Leslie, J., and Summerell, B. A., eds. 2006. The Fusarium Laboratory Manual. Blackwell Publishing, Ames, IA.

Maciel, J. L. N. 2011. Magnaporthe oryzae, the blast pathogen: Current status and options for its control. Plant Sci. Rev. 264:233-240.

Malaker, P. K., Barma, N. C. D., Tiwari, T. P., Collis, W. J., Duveiller, E., Singh, P. K., Joshi, A. K., Singh, R. P., Braun, H. J., Peterson, G. L., Pedley, K. F., Farman, M. L., and Valent, B. 2016. First report of wheat blast cause by Magnaporthe oryzae pathotype triticum in Bangladesh. Plant Dis. 100:2330.

McMullen, M., Jones, R., and Gallenberg, D. 1997. Scab of wheat and barley: A re-emerging disease of devastating impact. Plant Dis. 81:1340-1348.

Notomi, T., Okayama, H., Masubuchi, H., Yonekawa, T., Watanabe, K., Amino, N., and Hase, T. 2000. Loop-mediated isothermal amplification of DNA. Nucleic Acids Res. 28:e63.
Oh, H. S., Tosa, Y., Takabayashi, N., Nakagawa, S., Tomita, R., Don, L. D. Kusaba, M., Nakayashiki, H., and Mayama, S. 2002. Characterization of an Avena isolate of Magnaporthe grisea and identification of a locus conditioning its specificity on oat. Can. J. Bot. 80:1088-1095.

Peng, J. L., Zhou, Y. L., and He, Z. H. 2011. Global warning against the spread of wheat blast. J. Triticeae Crops 31:989-993.

Perelló, A. E., Martinez, I., and Molina, M. 2015. First report of virulence and effects of Magnaporthe oryzae isolates causing wheat blast in Argentina Plant Dis. 99:1177.

Perelló, A. E., Martinez, I., Sanabria, A., Altamirano, R., and Sibole, J. V. 2017 Pathogenicity of isolates of Magnaporthe spp. from wheat and grasses infecting seedling and mature wheat plants in Argentina. Plant Pathol. 66: $1149-1161$

Picinini, E. C., and Fernandes, J. M. C. 1990. Occurrence of wheat blast Pyricularia oryzae in commercial fields in the state of Rio Grande so Sul Brazil. Fitopatol. Bras. 15:83-84.

Pieck, M. L., Ruck, A., Farman, M., Peterson, G. L., Stack, J. P., Valent, B., and Pedley, K. F. 2017. Genomics-based marker discovery and diagnostic assay development for wheat blast. Plant Dis. 101:103-109.

Sadat, M. A., and Choi, J. 2017. Wheat blast: A new fungal inhabitant to Bangladesh threatening world wheat production. Plant Pathol. J. 33:103-108.

Sarver, B. A. J., Ward, T. J., Gale, L. R., Botz, K., Kistler, H. C., Aoki, T. Nicholson, P., Carter, J., and O'Donnell, K. 2011. Novel Fusarium head blight pathogens from Nepal and Louisiana revealed by multilocus genealogical concordance. Fungal Genet. Biol. 48:1096-1107.

Saunders, D. A. 1994. Wheat in heat-stressed environments: Irrigated, dry areas, and rice-wheat farming systems. In: Proc. Int. Conf.: Wheat in Hot, Dry, Irrigated Environments and Wheat in Warm Area, Rice-Wheat Farming Systems. CIMMYT, Wad Medani, Sudan.

Shewry, P. R. 2009. Wheat. J. Exp. Bot. 60:1537-1553.

Stack, J. P., Bostock, R. M., Hammerschmidt, R., Jones, J. B., and Luke, E. 2014 The National Plant Diagnostic Network: Partnering to Protect Plant Systems. Plant Dis. 98:708-715.

Tosa, Y., Hirata, K., Tamba, H., Nakagawa, S., Chuma, I., Isobe, C., Osue, J., Urashima, A. S., Don, L. D., Kusaba, M., Nakayashiki, H., Tanaka, A., Tani, T., Mori, N., and Mayama, S. 2004. Genetic constitution and pathogenicity of Lolium isolates of Magnaporthe oryzae in comparison with host speciesspecific pathotypes of the blast fungus. Phytopathology 94:454-462.

Urashima, A. S., Grosso, C., Stabili, A., Freitas, E., Silva, D., Netto, D., Franco, I., and Bottan, M. 2009. Effect of Magnaporthe grisea on seed germination, yield and quality of wheat. Pages 267-277 in: Advances in Genetics, Genomics and Control of Rice Blast Disease. G. L. Wang and B. Valent, eds. Springer, Dordrecht, The Netherlands.

Urashima, A. S., Igarashi, S., and Kato, H. 1993. Host range, mating type, and fertility of Pyricularia grisea from wheat in Brazil. Plant Dis. 77:1211-1216.

Viedma, L. Q. 2005. Wheat blast occurrence in Paraguay. (Abstr.) Phytopathology 95:S152.

Viji, G., Wu, B., Kang, S., Uddin, W., and Huff, D. R. 2001. Pyricularia grisea causing gray leaf spot of perennial ryegrass turf: Population structure and host specificity. Plant Dis. 85:817-826.

Villari, C., Mahaffee, W. F., Mitchell, T. K., Pedley, K. F., Pieck, M. L., and Hand, F. P. 2017. Early detection of airborne inoculum of Magnaporthe oryzae in turfgrass fields using a quantitative LAMP assay. Plant Dis. 101:170-177.

Zhang, N., Luo, J., Rossman, A. Y., Aoki, T., Chuma, I., Crous, P. W., Dean, R., De Vries, R. P., Donofrio, N., Hyde, K. D., Lebrun, M.-H., Talbot, N. J., Tharreau, D., Tosa, Y., Valent, B., Wang, Z., and Xu, J.-R. 2016. Generic names in Magnaporthales. IMA Fungus 7:155-159. 